\title{
OPTIMAL HEAT FLUX IN INTERMITTENTLY HEATED BUILDINGS
}

\author{
Rejhana Blazevic, Armin Teskeredzic \& Ehlimana Jugo
}
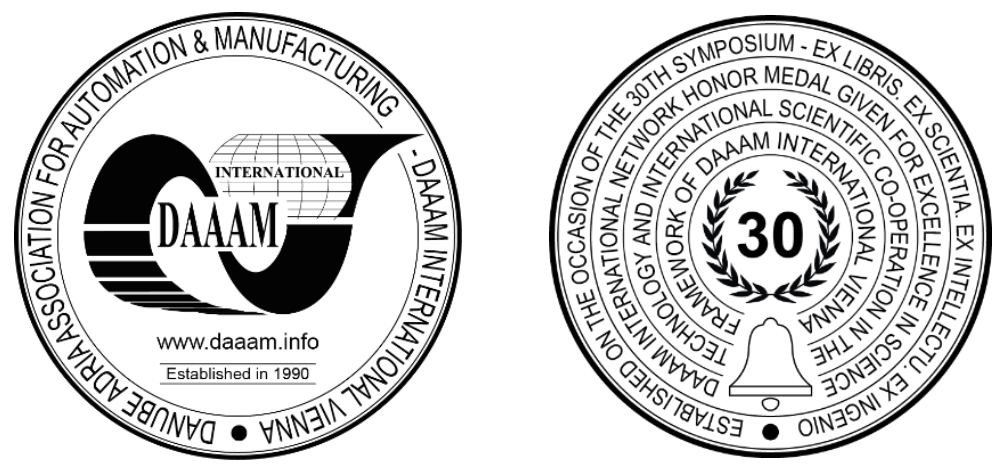

This Publication has to be referred as: Blazevic, R[ejhana]; Teskeredzic, A[rmin] \& Ehlimana, J[ugo] (2019). Optimal Heat Flux in Intermittently Heated Buildings, Proceedings of the 30th DAAAM International Symposium, pp.0701-0708, B. Katalinic (Ed.), Published by DAAAM International, ISBN 978-3-902734-22-8, ISSN 1726-9679, Vienna, Austria DOI: 10.2507/30th.daaam.proceedings.096

\begin{abstract}
Key role of the well-functioning heating system is to achieve desired thermal comfort conditions within the treated space with minimum possible energy consumption. The weather compensated control of the heating system is proposed as the most efficient and appropriate for this purpose. This paper provides results of the transient heat flow analysis in one representative room within well insulated and thermally massive building with intermittent heating. Developed calculation procedure is used and applied for comparison between calculated and measured values for the room temperature and heat flux from the radiator and the results are discussed. Additionally, an optimal heat flux is calculated for the same boundary and initial conditions by taking into consideration the time variation of the outside temperature and thermal inertia of the outer and inner walls. Optimal heat flux is calculated by assuming the variable heat source with capacity limit based on the existing radiator size. The task of this optimal and variable heat source is to achieve and keep the room temperature at previously prescribed value. The results of calculations are analyzed and discussed and the recommendations for the existing system settings are proposed. It is concluded that the model with optimal heat flux calculation can be used for determination of the optimal start-up of the heating system and the change of the control settings parameters. Further improvement of the existing model is elaborated and the extension to 3D calculations is proposed.
\end{abstract}

Keywords: heat flux; heating system; thermal inertia; intermittently heated building; thermal comfort

\section{Introduction}

Energy efficiency has become one of the main pillars for achieving policy goals regarding the energy transition strategies [1]. Energy consumption in buildings contributes with $40 \%$ of the total energy consumption at the level of European Union member states [2] and as such represents one of the key target sectors for interventions. As a result, energy strategic documents underline the importance of energy efficiency in buildings such as long term strategies of refurbishment of the existing buildings stock [3], central government buildings and are also providing plans for future near zero energy buildings [2].

Over the past few decades, heating systems have been traditionally sized based on the design outdoor conditions and by using steady state approach. Moreover, these systems were almost always oversized and in case of the buildings refurbishment and decreasing the energy need at the same time introduce additional difficulties for the proper control of existing heating systems. Calculated heat losses of the building for design conditions are relevant for the system sizing. 
For calculated losses the heating bodies and the heat source are usually sized with the safety factor. In general, when the heating system operates for 24 hours per day, the transient effects are not significant. At the other side if the intermittent heating is applied, especially for long defined setback operation, transient effects become very important and cannot be neglected. Therefore, the analysis of the transient behaviour of the building with constantly changing external and/or internal conditions, becomes extremely important and dynamic simulations are used to provide more accurate prediction [4], [5].

The weather conditions have the main influence on the overall heat demand of a building. In cold periods, the building requires more energy for heating, and vice versa. As the weather conditions constantly changes, so the heating demand of the building also changes. Compensating for the weather influence is therefore one of the best ways to achieve energy savings.

From existing advanced heating control types, the most heating systems use a weather compensation for heating control. Weather compensated heating systems use a temperature sensor placed on the outside of the building to adjust the system controls and compensate the changes in outside temperature automatically [6], [7], [8]. The goal is to keep building at a constant 'comfortable' temperature. Weather compensation control is recognised as an efficient heating control for underfloor and radiator heating system as well as for district heating system. Weather compensation is a useful way to provide thermal comfort and to improve the efficiency of all heating systems but not enough good.

During the last decade, many research groups studied different aspects of Model Predictive Control (MPC) applied to the building thermal control. Analysis conducted in [9], [10] is focused on providing optimal temperature control in order to ensure thermal comfort. MPC has ability to use occupancy schedule and weather forecasts for optimal temperature control, and that is the main reason for its wide application in intermittently occupied buildings. A new cost function is proposed for MPC in [10] which ensures the thermal comfort in the building with minimal energy consumption. That cost function is linear which allows the problem to be solved by using the Linear Programming (LP) method. Also, a comprehensive report about development and validation of the dynamic model of a representative building is given in [11] in which the modular Model Predictive Control (MPC) system is presented. A novel formulation of the model predictive temperature control problem in buildings is given in [12].

In order to provide thermal comfort in building with minimal energy consumption, the heating system should ensure temperature control at certain limits and with a certain reaction rate. In intermittently heated buildings, this is even more difficult to achieve because of the variable temperature set point during the time. There are usually two values of desired temperature, the set temperature value while the heating system is ON and the setback temperature value while the heating system is ON only if the water supply temperature is less than desired value, otherwise the system is OFF. If one sets the low desired value for the setback operation, the system would be almost always OFF. In both cases an open loop control is applied, since the control variable (room air temperature) is maintained via appropriate water supply temperature.

In this paper an analysis of the existing system with weather compensated control is performed. An optimal heat flux based on the building needs is calculated and the results of calculations are used to improve existing control parameters, including recommendations for system improvement.

\section{Temperature solver and physical assumptions}

Temperature Solver is based on the methodology and the calculation procedure, described in details in [4]. In this paper, the developed Temperature Solver is applied for transient heat balance analysis of one representative room. Energy management system is installed in the building which collects and stores the hourly data of measured variables into the central database. This system is used to provide an input data for the current analysis, and the following variables are used: the supply radiator temperature, the outside temperature and the room air temperature. Geometry of the room is known including the thermo-physical properties of multi-layer outside wall, internal wall dimensions and properties, windows size and its known $\mathrm{U}$ value as well as the installed radiator capacity and type.

The observed room is placed at the side corner of the large educational building. All internal walls are neighbouring heated spaces and there are two outer surfaces with windows and a parapet wall. Energy efficiency measures were implemented three years ago - the thermal insulation is added to all outside walls, old windows were replaced and the new efficient condensing boiler was installed.

The heating system is designed as a two pipe system treating the whole building as a single zone. The weather compensated control is implemented which controls the water supply temperature from the boiler according to the outside temperature. The time constant of the boiler control is set on 11 hours which means that the measured outside temperature is averaged over 11 hours and it is used to set the water supply temperature. There are no thermostatic valves at radiators and the water flow in the distribution system is constant, independently from the variation of the outside temperature. Heating system operates according to the prescribed occupancy schedule with 10 hours of heating per working day and only 4 and 2 hours of heating during the Saturdays and Sundays, respectively. The building is well insulated with high internal thermal mass and the prescribed heating schedule causes the strong transients regarding the room air temperature.

The geometry of the observed room is shown in Figure 1. Size of the room is 6,7/3,4/3,46 in meters (W/L/H). The observed room consists of two outer walls with the same structure and with total area of $27,4 \mathrm{~m}^{2}$. Outer exposed surface consists of 6 windows and total windows area is $3,00 \times 2,35 \mathrm{~m}$. There are two four column cast iron radiators in the room which are placed at the two outside walls. One of the installed radiators is Jadran 600/4-18 with a nominal power of 
$Q_{\text {rad }}^{N}=2736 \mathrm{~W}$ and the other is Jadran 600/4-9 with a nominal power of $Q_{\mathrm{rad}}^{N}=1638 \mathrm{~W}$, both corresponding to the standard $90 / 70 / 20^{\circ} \mathrm{C}$ temperature regime.

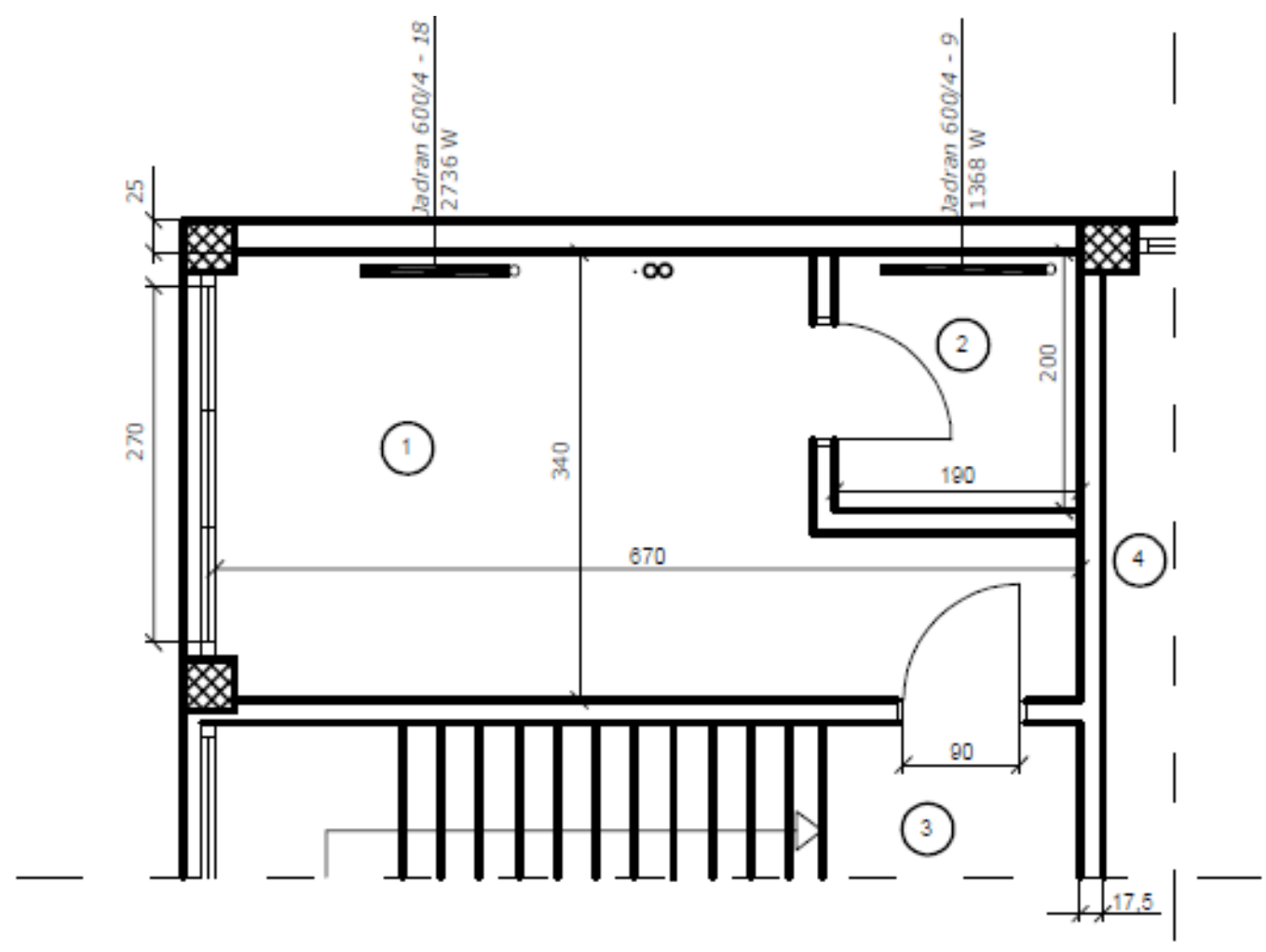

Fig. 1. The geometry of observed room

Input variables required for the Temperature Solver tool are hourly measured values of the $T_{\text {out }}$ as an ambient or outside air temperature and $T_{S}$ as the radiator supply temperature. Room air temperature is defined as $T_{\text {room }}, Q_{\text {rad }}$ as the current radiator heat flux, $T_{i w a}$ as average internal walls temperature, and $T_{R}$ as the return water temperature are unknown variables and will be the output values of the tool [4].

The following assumptions are used to model the room heat balance. A room is presented with one computational cell, which implies uniform room air temperature over its volume. The radiator body thermal mass is added to the hot water thermal mass as presented in [4]. It is assumed that all inner walls (upper, side, and floor walls) are represented with one thermal mass element.

Thermo-physical properties of 4 different layers of the outer wall are given in the Table 1 . Initial room temperature is assumed as $19^{\circ} \mathrm{C}$ which corresponds to the measured initial value and initial inner wall temperature is set to $19,3^{\circ} \mathrm{C}$. It is assumed that convective heat transfer coefficient from inner walls towards room air is $8 \mathrm{~W} / \mathrm{m}^{2} \mathrm{~K}$, convective heat transfer coefficient between outer wall and outdoor air is $24 \mathrm{~W} / \mathrm{m}^{2} \mathrm{~K}$, and the total area of inner walls is $150 \mathrm{~m}^{2}$, with corresponding convective heat transfer coefficient of $5 \mathrm{~W} / \mathrm{m}^{2} \mathrm{~K}$. Assumption of Biot number less than 0,1 is applied for the inner walls, which is than consistent with the proposed calculation approach.

The total mass of the inner walls is $5000 \mathrm{~kg}$ with the mean specific heat of $1600 \mathrm{~J} / \mathrm{kgK}$. Overall heat transfer coefficient of the outside walls is $U_{\text {wall }}=0,322 \mathrm{~W} / \mathrm{m}^{2} \mathrm{~K}$ and it is calculated based on the data given in Table 1 . U value for window is taken from the manufacturer catalogue and it is $\mathrm{U}_{\text {win }}=1,6 \mathrm{~W} / \mathrm{m}^{2} \mathrm{~K}$, while the number of air changes per hour is estimated and it is set to value of $0,2 \mathrm{~h}^{-1}$ which is kept constant during the calculation.

\begin{tabular}{|c|c|c|c|c|c|}
\hline Layer & Material & $\begin{array}{c}\text { Thickness, } \\
\mathbf{m}\end{array}$ & $\begin{array}{c}\text { Thermal conductivity, } \\
\mathbf{W} / \mathbf{m K}\end{array}$ & $\begin{array}{c}\text { Specific heat, } \\
\mathbf{J} / \mathbf{k g K}\end{array}$ & $\begin{array}{c}\text { Density, } \\
\mathbf{~ k g} / \mathbf{m}^{\mathbf{3}}\end{array}$ \\
\hline 1. & Cement mortar & 0,025 & 1,4 & 2100 & 1050 \\
\hline 2. & EPS & 0,1 & 0,04 & 1260 & 20 \\
\hline 3. & Hollow brick & 0,25 & 0,64 & 1600 & 920 \\
\hline 4. & Lime mortar & 0,025 & 0,81 & 1600 & 1050 \\
\hline
\end{tabular}

Table 1. Thermo-physical properties of outer walls 


\section{Results and discussion}

In this section analysis of the operation of the heating system was elaborated first and then the obtained calculation results are analysed and compared with measured data. Temperature solver is used for calculation of room temperature, radiator heat flux, return water and inner wall temperature. Initial and boundary conditions were applied according to data given in previous subsection. The calculation is run as transient with prescribed variable outside temperature and measured value of radiator supply temperature, both shown in Figure 2. Since the time step for calculations is set as 10 minutes or $600 \mathrm{~s}$ the boundary condition values such as outside temperature and water supply temperature are interpolated between the hourly known values. Calculated values are then compared with measured values.
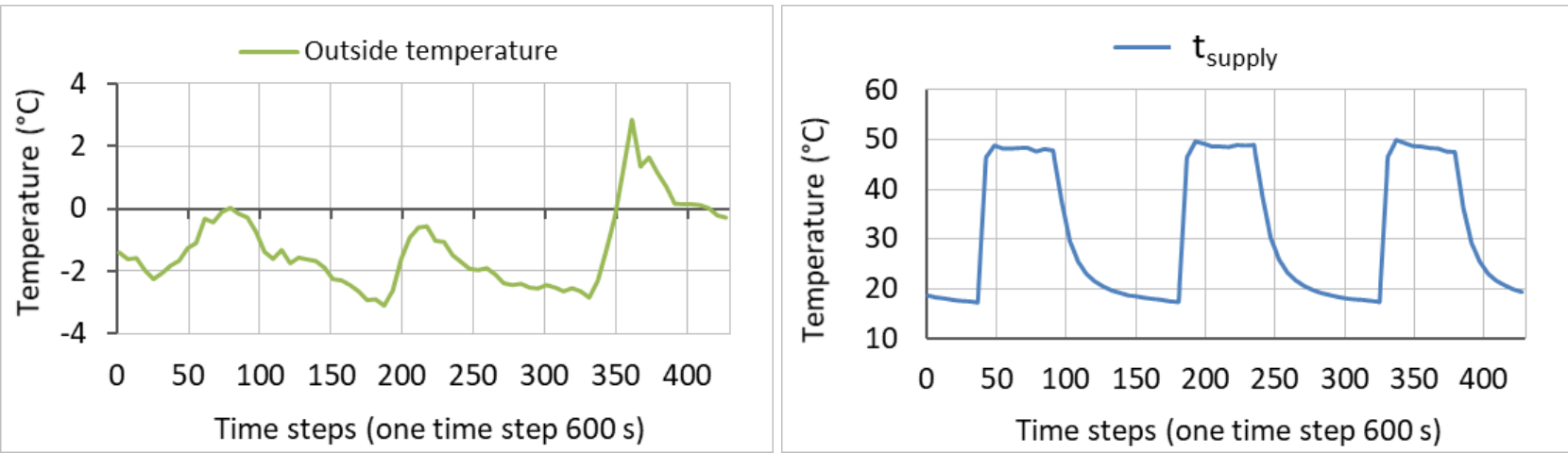

Fig. 2. Outside air temperature profile (left) and water supply temperature (right)

Figure 2 left shows the variation of the measured outside temperature values and the Figure 2 right shows the measured supply water temperature used as input parameter in the calculations. Comparison of measured and calculated results by the Temperature Solver are shown in Figure 3.

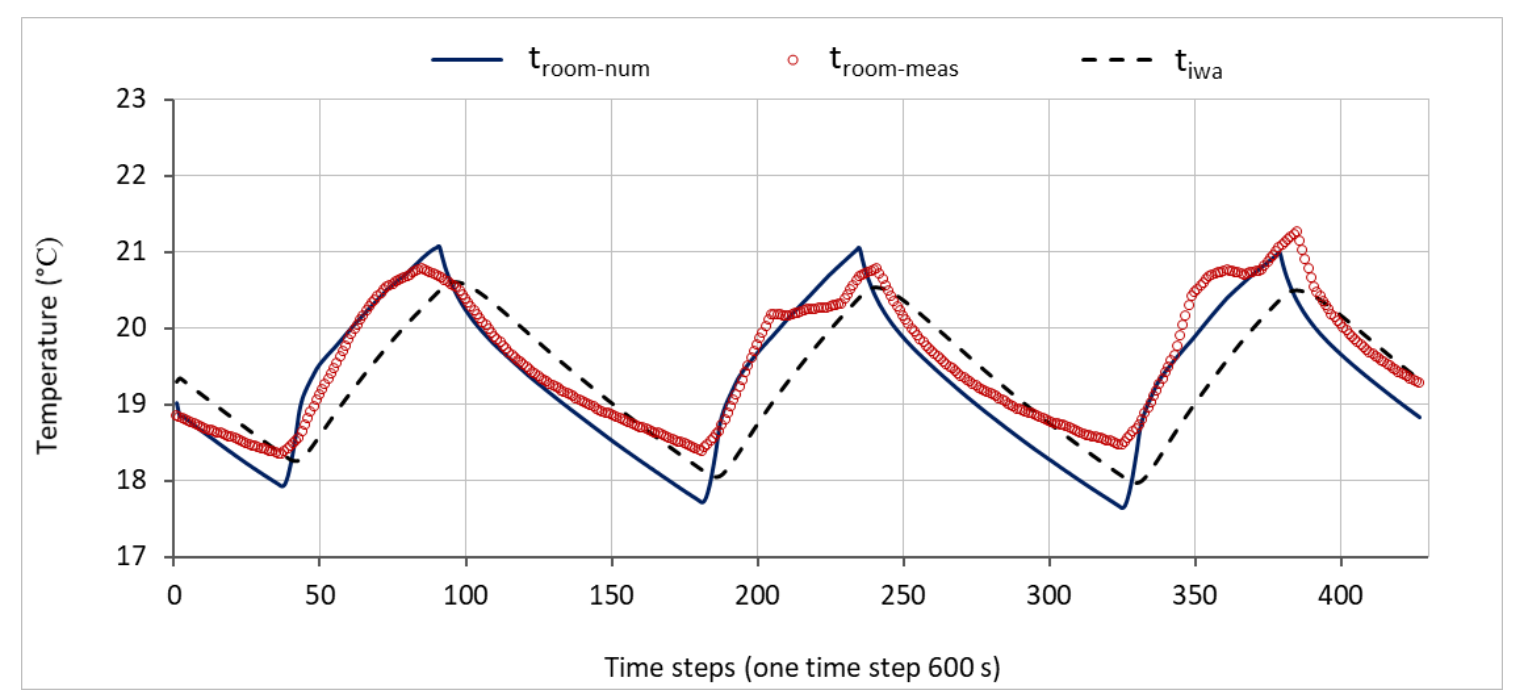

Fig. 3. Comparison of measured (red circles) and calculated values (blue line) of room air temperature and temperature of inner walls (dashed black line) during calculation period

Figure 3 shows strong transient behaviour of the room temperature during the three full days of analysis and it can be seen that the steady-state room temperature has never been reached within this period (see the measured values represented by circles). Calculated values of the room temperature are represented with full blue line while the inner wall temperature is given as a dashed black line (Figure 3). It can be noticed that the very good agreement between calculated and measured room temperature values has been obtained, which is mostly due to the correctly guessed inner walls temperature as well as the inner walls thermal mass. It should be said that the calculation without the existence of inner walls, by assuming their thermal mass as zero, show significantly different profile of the room temperature. In this case the room temperature has significantly higher value during the periods where the heating system is ON while during night when the system is OFF the room temperature drops below $15^{\circ} \mathrm{C}$. This means that the inner walls play significant role in the overall heat room balance in the buildings with intermittent heating, which cannot be neglected. At the other side, the weather compensated control would be probably the most appropriate way of control if the heating system is constantly ON. However, the system schedule in this case influences the overall heat balance and the thermal comfort conditions at 
the end. This means that if the building is significantly subcooled for example during long periods when the system is OFF it would be hard or almost impossible to achieve the desired level of thermal comfort.

The derivation of the heat curve, which is the basis for the weather compensated control, implies the steady state conditions in which neither the thermal inertia of the outside walls nor the thermal inertia of the internal walls is taken into consideration. The weather compensated control has another parameter - the time constant which can help with the fact that there is a phase shift between the outside temperature variation and the heat flux from the room. However, this time constant does not help much in cases where the inner walls are significantly subcooled. This observation holds for well insulated, intermittently heated buildings with high thermal inertia of inner walls.

The comparison of measured and calculated results by the Temperature Solver are shown in Figure 4 and Figure 5. There is an excellent agreement between calculated and measured heat flux values (Figure 4) as well as between calculated and measured return water temperature (Figure 5).

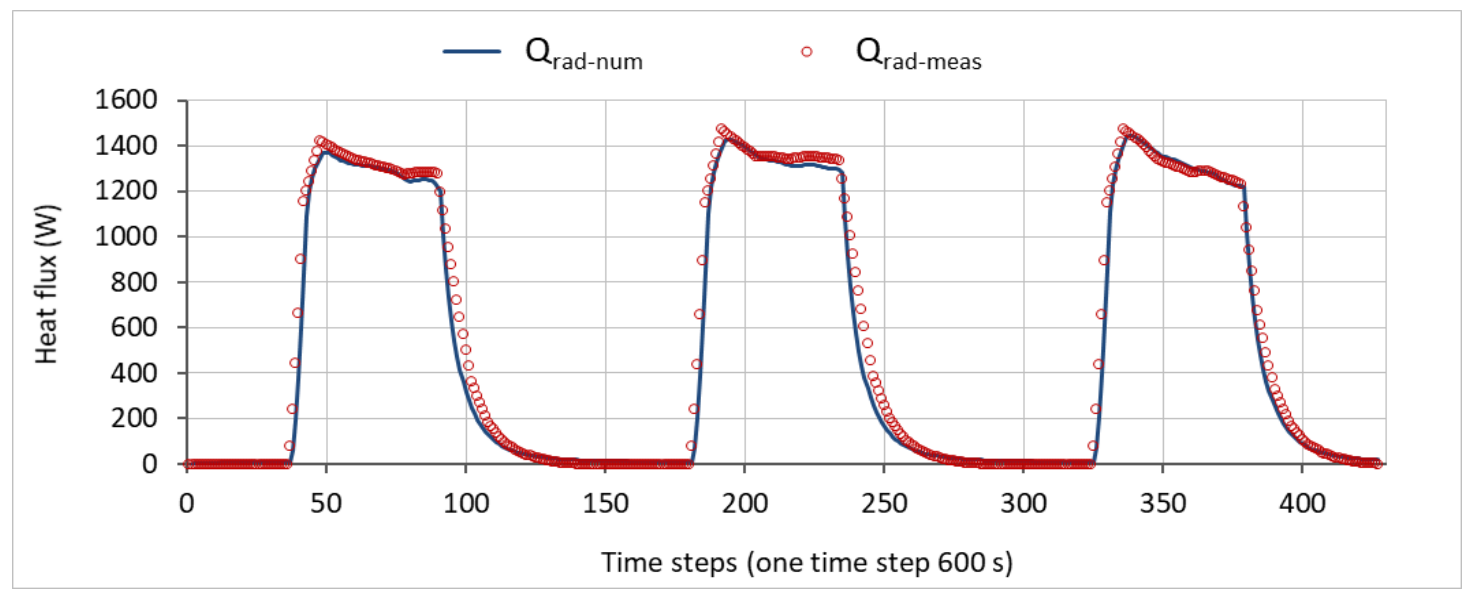

Fig. 4. Comparison of measured and calculated values of radiator heat flux

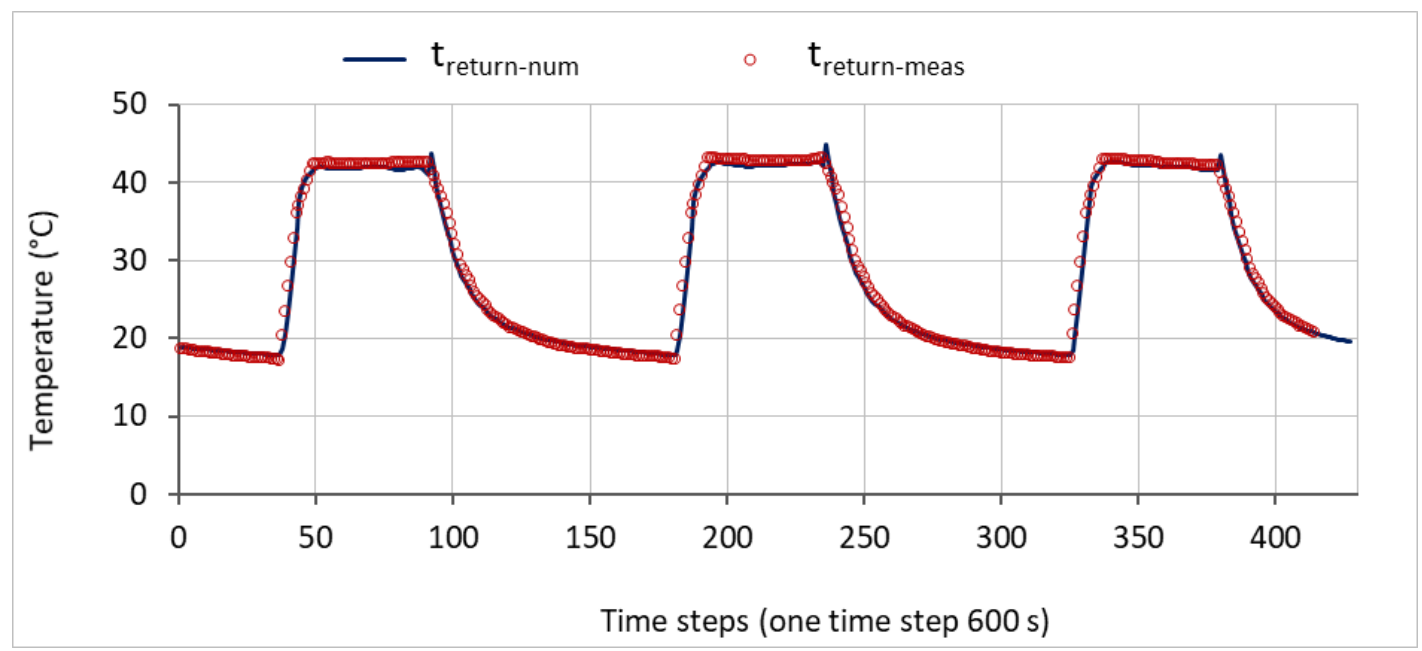

Fig. 5. Comparison of measured and calculated values of water return temperature

Figure 4 shows the heat flux from the radiator which is calculated based on the room air temperature and mid temperature of the radiator body. It can be noticed that the heat flux is highest at the first hour of heating which is due to the control settings. The supply water temperature is set for $20 \%$ overshoot during the first hour of heating after the setback. This is set in order to compensate the heat losses during the night setback. Figure 5 shows the comparison between the measured and calculated water return temperature and again the agreement is very good. It can be noticed that the return water temperature is low resulting in the full condensation mode which decreases the natural gas consumption. It can also be observed that the thermal inertia of the radiator plays an important role, since the heat flux from radiator gradually decreases in time after the heating system was OFF.

The room air temperature which is in primary focus of our analysis (see Figure 3) shows that the set room temperature of $21^{\circ} \mathrm{C}$ has not been reached during the first two days. Also, the limit thermal comfort temperature defined as $20^{\circ} \mathrm{C}$ is reached quite late for all three days of analysis. This means that the existing system has still room for improvement. 
In the current work the calculation of the optimal heat flux is implemented in order to support the heating system operator to optimise the settings at the boiler control. This optimal heat flux calculation should result in two major improvements. One is to reach the limit thermal comfort temperature earlier during the working day and the other is to keep the set temperature (in this case $21^{\circ} \mathrm{C}$ ) constant in time despite the variation of the heat flux caused by the variation of the outside temperature. Calculation of the optimal heat flux with existing tool requires the intervention at the calculation matrix, which is not the topic of this paper and will not be elaborated. Optimal heat flux will be incorporated as variable heat source which will recover all heat losses from the room while keeping the room temperature at the set level. It will replace the radiator but its capacity will be limited by the size of the existing radiator. This implicitly assumes that the temperature regime of the heating system will not be changed. Analysis will be targeted to intervention on the heating schedule and proposing the new setback temperature which will avoid the sub-cooling of the building components.

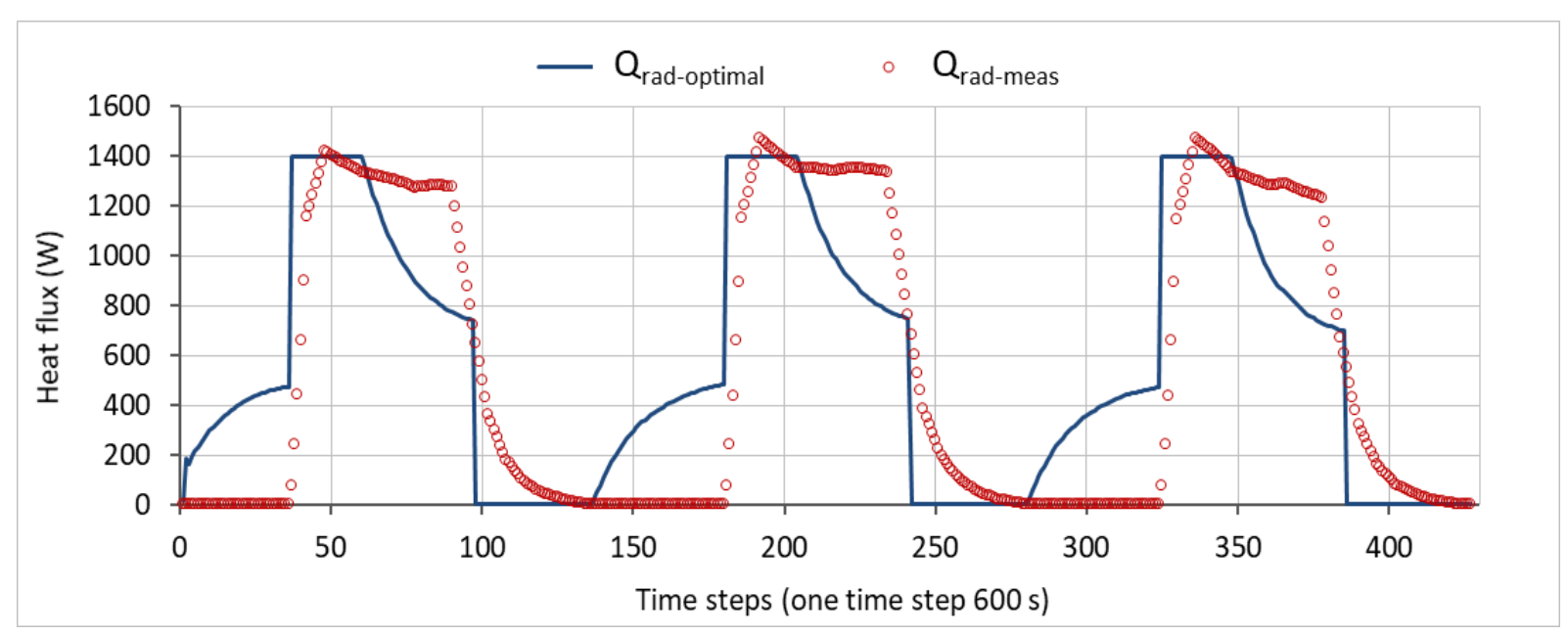

Fig. 6. Optimal calculated radiator heat flux versus measured heat flux

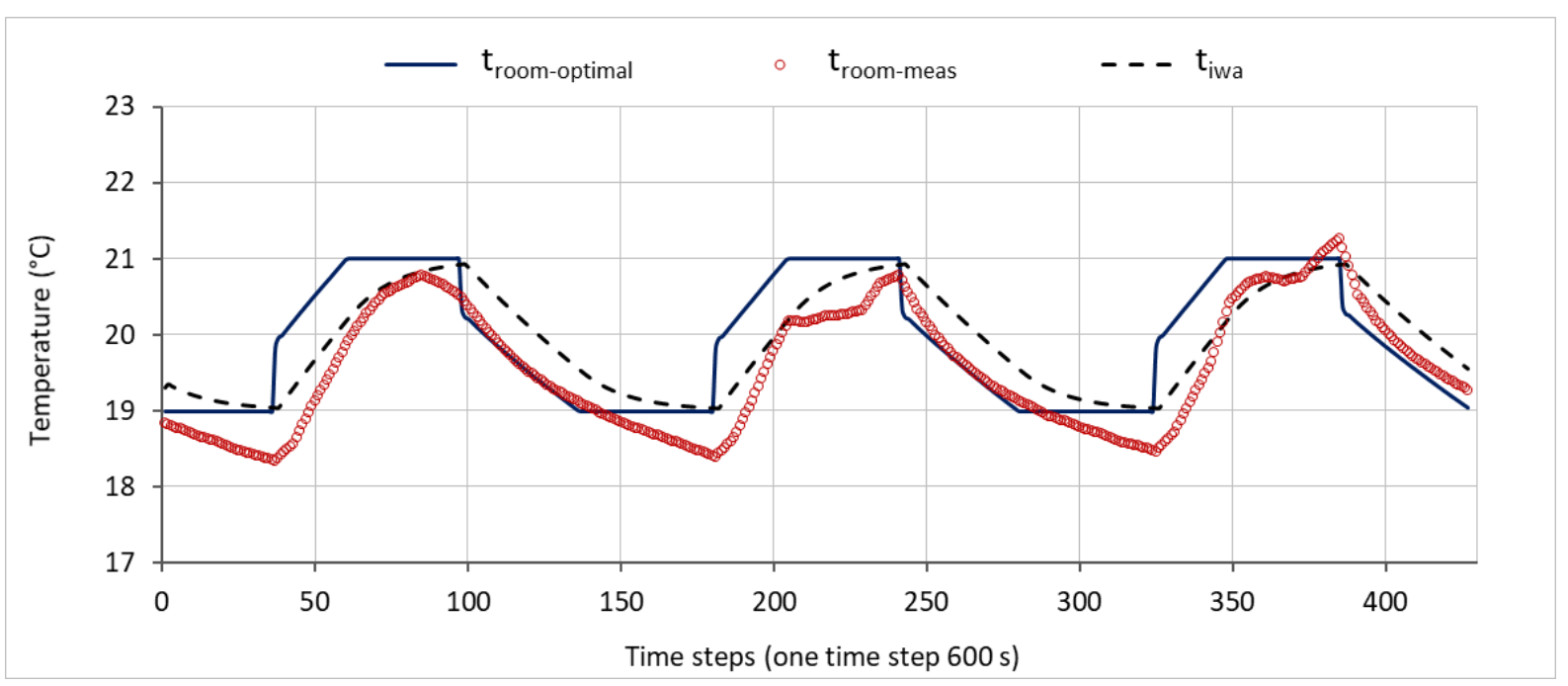

Fig. 7. Comparison of measured and calculated room air temperature values for optimal heat flux

Figure 6 shows the comparison of calculated optimal heat flux and existing measured heat flux. It can be observed that the maximum heat fluxes are approximately at the same level but it can also be noticed that the profile of the heat flux is different for the optimal case. An optimal heat flux is more intensive at the prescribed start time, while its value gradually decreases from the midday onwards, when the steady-state prescribed temperature is reached. Also, due to the fact that the night setback temperature is set to $19^{\circ} \mathrm{C}$ the heat flux exists in optimal case even during the night and does not allow the inner wall temperatures to go beyond $19^{\circ} \mathrm{C}$. When the occupied period is over and the system should be switched OFF it can be seen that the radiator still exchange the heat with the room air because of the thermal inertia of the radiator body. In optimal case the heat flux drops sharply because its value is always calculated based on the current needs. Since at this moment the setback temperature $\left(19^{\circ} \mathrm{C}\right)$ becomes relevant, due to the fact that the room air is at $\sim 21^{\circ} \mathrm{C}$, the optimal flux becomes zero! 
Figure 7 shows that for optimal case the room air temperature is achieved earlier and that it is kept constant during the rest of the day. It also shows that the night setback temperature is preserved at the level of $19^{\circ} \mathrm{C}$ as required. The shape of the optimal heat flux (Figure 6) tells us also that the installation of the thermostatic valves would be beneficial in this case. Thermostatic valve would reduce the water flow through the radiator and this should result in gradually decreased heat flux from the radiator towards the room. When the heat flux between the room and the inner walls is small the temperature in the room is rising, which indicates that the existing system is oversized. This can be shown by calculating the ratio between the room heat losses and heat gains from the radiator in steady-state for any outside temperature. It can be shown that the heat gains prevail causing the rise of the room air temperature and this is valid in cases where heat exchange with inner walls can be neglected.

The final conclusion is that the proper settings of the night setback temperature and installation of the thermostatic valves would result in the optimal energy use by satisfying the thermal comfort conditions. Existing tool is used for analysis of existing data, for calculation and comparison with measured values and for proposing the proper control settings. The tool also provides the play field in which many other options can be tested.

\section{Conclusion and further work}

This paper demonstrates the applicability of the previously developed solution algorithm on a real case example. In the first part of the analysis the calculated results for one representative room in the observed building are compared with measured values extracted from the building energy management system. The measured and calculated results are discussed with all relevant physical parameters influencing the room heat balance. It is observed that the room air temperature has not been achieved for the existing case, despite the proper set value at the weather compensated boiler controller. It is also recognized that the limit thermal comfort condition temperature has been reached lately during the day and it is concluded that the problem introduces strong transient behaviour of the room air temperature which almost never reaches the steady-state condition.

In the second part of the work an optimal heat flux calculation procedure has been introduced and shortly described. This procedure is applied on the same problem with the goal to optimise the heat schedule for the building and avoid mentioned problems. The night setback temperature is defined in the calculation example providing an optimal heat flux during the occupancy and the night periods. As a result the set temperature is achieved and maintained and the results are discussed. It is noticed that the optimal heat flux is more intensive at the moment when heating system is back from the setback position and also that from the midday onwards the required heat flux gradually decreases. Because of the nature and the shape of the optimal heat flux, the installation of the thermostatic valves is proposed. Proposed intervention should result in achieving the desired room air temperature faster and to satisfy the thermal comfort conditions with minimum required energy consumption.

Proposed approach can also be used for the fine tuning of the weather compensated control settings such as water supply temperature and/or for analysis of the temperature drop over the radiator(s) which can be achieved via corrections of the water flow in the radiator.

Developed methodology is however limited for cases in which observed room is surrounded with heated spaces, so that the heat exchange with neighbouring rooms is neglected. Also, all inner walls are represented via single thermal mass element, which due to the different structure of the side and roof walls, introduces additional modelling error. Finally, the assumption of small Biot numbers (less than 0,1) characteristic for heat transfer between the room air and inner walls limits the applicability of the methodology for cases where spatial temperature variation within inner walls is not significant.

Further development and application of the existing methodology will cover an extension to 3D problems, which is currently in progress. This approach will allow calculations for complex buildings with arbitrary shape of the envelope elements and will also overcome all aforementioned limitations.

\section{References}

[1] Action Plan for Energy Efficiency: Realising the Potential, Accessed on: 2019-03-13

[2] Directive 2010/31/EU of the European Parliament and of the Council of 19 May 2010 on the energy performance of buildings (EPBD). Off. J. Eur. Union, (2010). 153, pp. 13-35.

[3] Directive 2012/27/EU of energy efficiency (EED) of the European Parliament and of the Council of 25 October 2012. Off. J. Eur. Union, (2012). 315, pp. 1-56.

[4] Teskeredzic, A. \& Blazevic, R. (2018). Transient Radiator Room Heating-Mathematical Model and Solution Algorithm, Buildings, Vol. 8, No. 11, 2018, pp. 1-18., ISSN: 2075-5309, DOI: 10.3390/buildings8110163

[5] Blazevic, R. (2018). Advanced Modeling and Dynamic Simulation of the Heating System with the SimultaneousApplication of Modelica and the Final Volume Method, Ph.D. Dissertation, Enegy department, University of Sarajevo, Sarajevo, Bosnia and Herzegovina

[6] Viessman, Climate of innovation (2012). Control technology - Weather compensated controls

[7] Davidson, P. \& Pout, C. (2017). Evidence Gathering - Compensation and TPI Heating Controls, Building Research Establishment Ltd. (BRE), Report number: 1178/06/2016 (ETS Framework - Lot 18) Issue: 3 
[8] Dolinay, V. \& Vasek, L. (2013). Corrections of the heating curve based on begaviour in the consumption of the heat, International journal of mathematics and computers in simulation, Vol. 7, No. 1, 2013, pp. 25-32., ISSN: 1998-0159

[9] Ghiaus, C. \& Hazyuk, I. (2010). Calculation of optimal thermal load of intermittently heated buildings, Building and Environment, Vol. 42, 2010, pp. 1248-1258., ISSN: 0360-1323, DOI: doi:10.1016/j.enbuild.2010.02.017

[10] Hazyuk, I., Ghiaus, C. \& Penhouet, D. (2012). Optimal temperature control of intermittently heated buildings using Model Predictive Control: Part II - Control algorithm, Building and Environment, Vol. 51, 2012, pp. 388-394., ISSN: 0360-1323, DOI: 10.1016/j.buildenv.2011.11.008

[11] Crnokić B., Lješić G., Stojkić Ž. \& Bandić-Glavaš M. (2017). Analysis of energy consumption in the building asthe basis for development of the modular model predictive control system, Proceedings of the 28th DAAAMInternational Symposium, 8-11 November 2017 Zadar, ISBN 978-3-902734-11-2, ISSN 1726-9679, B. Katalinic (Ed.), pp. $0299 \quad-$ 0308, Published by DAAAM International, Vienna, Austria, DOI:10.2507/28th.daaam.proceedings.041

[12] Martinčević A., Vašak M., Lešić V. (2016) "Model predictive control for energy-saving and comfortable temperature control in buildings", IEEE, Control and Automation (MED), Athens 